\title{
Benefits and Environmental Determinants of Physical Activity in Children and Adolescents
}

\author{
Paul D. Loprinzi ${ }^{a} \quad$ Bradley J. Cardinal $^{b}$ Kristina L. Loprinzic, ${ }^{c}$ Hyo Lee \\ aLansing School of Nursing and Health Sciences, Department of Exercise Science, \\ Bellarmine University, Louisville, KY, ${ }^{b}$ Program in Exercise and Sport Science, School of \\ Biological and Population Health Sciences, College of Public Health and Human Sciences, \\ Oregon State University, Corvallis, OR, ' Lansing School of Nursing and Health Sciences, \\ Bellarmine University, ${ }^{d}$ Norton Hospital, Women's Pavilion, Louisville, KY, USA, e Department \\ of Sport and Health Sciences, Sangmyung University, Seoul, Korea
}

\author{
Key Words \\ Childhood $\cdot$ Correlates $\cdot$ Exercise $\cdot$ Youth
}

\begin{abstract}
In this review, we identify the health benefits associated with physical activity (PA); address the physical activity and sedentary guidelines issued by public health scientists as well as children's compliance to these guidelines; discuss the importance of motor skill acquisition during early childhood; and identify different settings that contribute to physical activity participation and strategies for improving PA in these settings. Results show that regular participation in PA during childhood has numerous immediate benefits, including positive changes in adiposity, skeletal health, psychological health, and cardiorespiratory fitness. Additionally, motor skill development during early childhood may have immediate health benefits as well as longlasting effects in adulthood. Furthermore, the benefits of PA during childhood also appear to positively influence adult health outcomes, such as increased bone mineral density. Key environmental settings that have been shown to influence children's PA behavior include child care, active commuting to and from school, school recess, school physical education, afterschool programs, churches, medical settings, and the home environment. Recommendations for practitioners and researchers are discussed.


Regular participation in physical activity (PA) is important for good health in children and adolescents (i.e., 6-19 years of age). However, despite the importance of PA, a large proportion of children are not getting sufficient levels of daily PA. Specifically, non-Hispanic black and Hispanic children are less likely than non-Hispanic white children to report involvement in organized PAs [1]. To help inform policies and programs to promote PA in children, this review will detail areas surrounding PA and health in children. First, the health benefits associated with PA in children will be addressed. Second, the link between childhood PA and adult health will be examined. Third, the importance of motor skill acquisition during early childhood will be discussed. Fourth, the PA and sedentary guidelines issued by public health scientists will be outlined as well as children's compliance to these guidelines. Fifth, the different settings that contribute to PA participation as well as strategies for improving PA in these settings will be identified. Our goal is not to provide an exhaustive systematic review of the PA literature in children and adolescents, as several authors have done so previously, often reviewing the same, overlapping evidence. Rather, we will, in detail, identify key environmental settings and determinants that influence activity behavior in children and adolescents and delineate strategies that can be used to influence PA in this population. Current relevant review papers will be summarized; otherwise, the findings of recent original studies will be addressed. Finally, this paper will conclude with recommendations for researchers and practitioners.

\section{Health Benefits of Physical Activity}

To inform PA-related policies and to contribute to chronic disease prevention, Twisk [2] reviewed the literature examining the influence of adolescent PA on adolescent health status. On that basis, the following conclusions were made: i) there were inconsistent findings regarding the relation between PA and lipid levels, blood pressure and glucose levels; ii) PA was consistently positively associated with high-density lipoprotein levels, cardiorespiratory fitness, bone mass, and self-esteem; iii) PA was consistently negatively associated with adiposity and stress levels. These findings have also been supported by other studies [3] and indicate that health outcomes associated with PA [4], along with PA behavior itself [5], track over time, underscoring the importance of PA during childhood for both immediate and long-term health.

\section{Link between Childhood Physical Activity and Adult Health}

Childhood PA may influence adult health status in three ways: i) PA in childhood directly influences adult health outcomes (e.g., bone mineral density); 2) PA in childhood results in positive health outcomes that track into adulthood (e.g., BMI tracking from childhood to adulthood); and iii) PA behavior tracks from childhood to adulthood [6].

With regard to the direct effect of childhood PA on adult health status, the evidence appears to be dependent on the health outcome. Epidemiological studies demonstrate that participation in sports during childhood is not associated with cardiovascular disease or coronary risk factor status during adulthood [7]. However, with respect to skeletal health, studies have found a significant positive association between time spent playing sports at age 12 and bone mineral density in women aged 20-23 years [8], suggesting that the ability to lay down adequate levels of bone during adulthood is influenced by PA behavior during childhood. 
Childhood PA can also influence adult health status indirectly through positive changes in health outcomes in children [6]. Presently, the link between childhood PA and adult health status becomes more evident as several of the health outcomes (e.g., BMI) associated with PA track from childhood into adulthood, suggesting that regular PA during childhood and adolescence may be of critical importance in the prevention of chronic disease later in life [9].

The Cardiovascular Risk in Young Finns study [9] examined the tracking of PA between adolescence and adulthood. A cohort of male and females, aged 9, 12, 15, and 18 years were followed at 3-year intervals for 9-12 years when they were $21,24,27$, and 30 years, respectively. Correlations were generally moderate, with the highest correlations for 3-year intervals and declining as the interval increased, suggesting that PA tracks better over shorter periods of time $(<3$ years).

\section{Importance of Motor Skill Acquisition in Early Childhood}

Often overlooked, learning to effectively move as a young child is an important skill underlying PA [10]. During early childhood development, motor skill acquisition is often cultivated through active play behavior such as galloping, hopping, leaping, running, and skipping. These locomotor skills form the foundation of future PA and movement competence [11]. If children do not have proficiency in these motor skills, then it is likely they will have limited opportunities for successful engagement in PAs later in life [10]. To develop and enhance children's motor competence, young children need to be taught a variety of different motor skills, and they require a sufficient degree of positive reinforcement for their mastery attempts in these motor skills [12].

To demonstrate the importance of motor skill acquisition in young children, Matvienko and Ahrabi-Fard [13] examined the effects of a 4-week after-school program on motor skills and fitness in kindergarten and first-grade children. Compared to control students who only participated in the assessments, the intervention group scored significantly better on all motor skill tests immediately following the intervention. Four months post intervention, children in the intervention group scored significantly better on various motor skill tests including jump rope, pull-ups, shuttle run, and throwing. Importantly, the results showed that rope-jumping and throwing skills were significant predictors of cardiovascular fitness at the 4-month followup. In support of these findings, Barnett and colleagues [14] showed that, among 244 children, those with good object control skills (e.g., kicking, catching, and throwing) were more likely to become fit adolescents. These findings are also supported by other studies [15]. An important take-home message from these studies is that motor skills, once learned, tend to be stable and enduring, more like traits, whereas fitness is a state. Although most studies in this area focus on the development of gross-motor skills, future studies are encouraged to examine the influence of hand-eye coordination and fine-motor skill cultivation on PA patterns and participation rates, as, arguably, these parameters may influence PA or perceptions of competence.

\section{Physical Activity and Sedentary Guidelines}

For desired health and behavioral outcomes, the US Department of Health and Human Services recommends that school-age youth (6-18 years) participate daily in 60 min or more of moderate to vigorous PA (MVPA) [16]. With regard to sedentary behaviors, the American Academy of Pediatrics recommends that children and adolescents reduce their sedentary (e.g., TV watching, computer use, video games, and telephone conversations) behavior to less than $2 \mathrm{~h}$ per day. 
Loprinzi et al.: Benefits and Environmental Determinants of Physical Activity in Children and Adolescents

\section{Compliance with Physical Activity and Sedentary Guidelines}

Despite the benefits of regular PA, a significant percentage of children and adolescents do not participate in the level of PA recommended by experts. The results of the most recent national CDC Youth Risk Behavior Survey indicate that only $36 \%$ of US high school students meet the 60-min MVPA guideline. Of concern, the prevalence of meeting the 60-min guideline was higher among male (44\%) than female $(28 \%)$ students, and higher in white (39\%) compared to African-American (30\%) and Hispanic (33\%) students [17]. Additionally, studies also show that non-Hispanic black and Hispanic children are less likely than non-Hispanic white children to report involvement in organized physical activities [1], emphasizing the importance of promoting PA in these populations. Furthermore, the promotion of PA during this time period is of particular importance given the noted decline in PA participation during the transition from adolescence to adulthood [18].

With regard to meeting sedentary guidelines, Marshall and colleagues [19] reviewed the extant literature involving prevalence of TV viewing in children and adolescents. Computer use was defined as using a computer outside of school hours for any purpose other than playing video game. Overall, $66 \%$ of children and adolescents watched TV less than 2 $\mathrm{h} /$ day. There were no gender differences between prevalence estimates for boys (66\%) and girls (70\%). Similarly, TV prevalence estimates were consistent across countries (i.e., USA = $70 \%$, European countries $=60 \%$, and Asia $=69 \%$ ). Overall, the evidence suggests that children and adolescents do not engage in sufficient amounts of PA.

\section{Physical Activity Participation in Different Settings}

There are numerous environmental settings for children to engage in PA, including actively commuting to and from school, recess/free playtime, physical education, and afterschool programs such as sports programs, community recreational programs (e.g., YMCA), dance classes, and boy/girl scouts. In addition to these after-school programs, the home environment is an important setting contributing to the PA behavior of children.

\section{Actively Commuting to and from School}

Often a neglected aspect of regular PA, actively commuting to and from school can be an important source of PA for school-aged children. Faulkner and colleagues [20] provided a systematic review of the literature describing whether children who actively commute to school are more physically active than children who travel by motorized transport. 11 of the 13 studies reviewed demonstrated evidence that children who actively commute to school, most often achieved by walking, were more physically active than those children who used motorized transport to school. Specifically, four studies reported a 20-min- difference in daily MVPA between those who actively commuted and those who took motorized transportation. Overall, these findings suggest that transport-related PA may make an important contribution to daily PA. When feasible and safe, children should be encouraged to actively commute to and from school. 


\section{Recess/Free Playtime}

During the school day, recess/free playtime offers children an opportunity to engage in regular PA, as the unstructure environment lends itself to the intermittent activity patterns of children [21]. Ridgers and colleagues [22] summarized the research literature on children's PA levels during playtime and the effect of playtime-based school interventions on children's PA behavior.

Ridgers et al. [22] reported 13 studies investigating the PA levels of children aged 4-12 years during school playtime. The playtime duration across the studies ranged from 16 to $35.5 \mathrm{~min}$. Playtime contributed up to $40 \%$ of the recommended MVPA a day for boys and up to $30.7 \%$ for girls, suggesting that playtime can make a considerable contribution to the accumulation of daily MVPA goals.

Ridgers and colleagues [22] reported five intervention studies investigating children's PA during playtime. Of these, three studies examined the effects of playground markings on children's PA [23-25], one study employed fitness breaks during playtime [26], and one study implemented games during playtime [27]. All three playground marking interventions increased PA levels during playtime. The fitness break intervention consisted of a 15-min break during playtime where children engaged in a 400-meter obstacle course that contained MVPA activities such as running and crawling. The fitness break intervention increased PA levels for both boys and girls during school playtime. For the games intervention, children engaged in a variety of different games that were designed to integrate MVPA into playtime. The games interventions showed that children were more active during the games program than during standard playtime. These findings suggest that not only should children be provided with free play opportunities on a daily basis, but providing active games and fitness breaks during playtime may also be a sensible strategy for increasing activity behavior during free play.

\section{Physical Education}

Physical education is another school setting that can provide children with an opportunity to engage in regular PA. Based on data from 17,766 adolescents in the 1996 US National Longitudinal Study of Adolescent Health, adolescents were more likely to engage in regular PA if they had daily physical education [28]. Despite the contribution that physical education has on daily PA, opportunities to engage in PA during physical education are limited. As of 2006 , only $3.8 \%$ of elementary schools, $7.9 \%$ of middle schools, and $2.1 \%$ of high schools offered students daily physical education for the entire year [29]. Three widely disseminated, evidenced-based school physical education curriculums that schools can adopt are the Sports Play and Active Recreation for Kids (SPARK) curriculum [30], the Child and Adolescent Trial for Cardiovascular Health (CATCH) program [31], and the Lifestyle Education for Activity Program (LEAP) [32].

\section{After-School Programs}

In addition to physical education at school, after-school programs have the capacity to reach large numbers of children and are thought to provide opportunities for children to engage in regular PA. Beets and colleagues [33] summarized the research literature examining after-school programs targeting youth PA. Using a meta-analysis strategy, 11 different after-school PA interventions were evaluated. Of these 11 studies, the mean effect size for 
interventions measuring PA was moderate (effect size $0.44 ; 95 \% \mathrm{CI} 0.28-0.6$ ). These results suggest that after-school programs that include a PA component can be effective at increasing PA levels among children. Before concrete after-school PA recommendations can be made, additional information on the following is needed: detailed information on the types of activities employed, information on the attendance rate, more comprehensive assessments of PA, and information on the fidelity of the intervention.

\section{Community-Based PA Opportunities}

In addition to schools, community-based PA programs are an ideal setting for promoting PA among children because they have the potential to reach a large percentage of children through a variety of different channels. These delivery channels include, but are not limited to, YMCA/YWCA, boy and girl clubs, boy and girl scouts, dance classes, local sports teams, summer schools/camps, religious institutions, and healthcare settings [34]. This section will discuss the effectiveness of PA interventions in summer school/camps, religious institutions, and healthcare settings since relatively few studies have been examined in the other community organizations.

\section{Summer School/Camps}

Jago and Baranowski [35] reviewed nine studies that examined the effectiveness of noncurricular interventions on promoting PA in children. Of these, two studies investigated the effects of a summer school/camp on children's activity behavior [36, 37]. A component of the Baylor GEMS pilot study [36] included 8-year-old African-American girls (above the 50th BMI percentile) attending a 4-week summer day camp that increased their exposure to enjoyable forms of PA, water, fruit, and vegetables. Following the camp, children were provided with a website link to help overcome PA and nutrition barriers. 12 weeks post intervention, PA levels showed no significant increase when measured by accelerometry or self-report. These findings are similar to those reported by Pate and colleagues [37]. Collectively, these results show that summer camp interventions do not elicit positive changes in children's PA behavior. However, before firm conclusions are made regarding the efficacy of summer camp interventions, additional studies are warranted.

\section{Religious Institutions}

Some of the advantages of faith-based institutions include large memberships, access to families, a presence in virtually every community, and connections to minority and low-income communities [38]. These characteristics provide a natural and convenient place for children to meet and participate in PA programs as well as to develop important behavioral skills related to regular participation in PA. In a faith-based obesity prevention trial conducted by Resnicow and colleagues [39], overweight African-American adolescents from 10 churches were randomized to participate in a high-intensity or moderate-intensity intervention. Participants in the high-intensity group met once a week for 6 months, and each session included an experimental interactive behavioral activity (targeting behaviors such as increasing fruit and vegetable intake, decreasing fat intake, and increasing PA), at least 30 min of MVPA, and preparation and/or consumption of low-fat meals or snacks. The moderate-intensity group met once a month for 6 months and discussed educational topics such as fat facts, barriers to PA, fat diets, neophobia, and benefits of PA. At 6-month follow-up, the net BMI difference between the highintensity and moderate-intensity groups was not statistically significant. These results suggest that church-based interventions have little influence on BMI; however, before firm conclusions are made regarding the efficacy of faith-based PA interventions, additional studies are needed. 


\section{Healthcare Setting}

Healthcare professionals are in a unique position to promote PA in young people as they are viewed as highly credible sources of health information. Healthcare professionals can promote PA in their young patients by: i) directly counseling youth on the benefits of exercise and helping them formulate a plan to become physically active; ii) teaching parents how to provide emotional and tangible support for their children's PA; and iiii) becoming an advocate for school-based and community-based PA programs [34]. Although numerous studies have evaluated the effectiveness of primary care-based PA interventions in the adult population [40], very few studies have systematically evaluated this approach in children and adolescents. Intervention studies conducted by Patrick et al. [41] and Ortega-Sanchez et al. [42] show that physician-based counseling is an effective method to increase children's activity levels and reduce sedentary behaviors. Evidence from these studies suggests that physicianbased counseling coupled with stage-appropriate written materials can be effective at increasing PA among adolescent youth.

\section{Home Environment}

The home environment is an important setting contributing to the PA behavior of children. Parents can influence their children's participation in PA through a variety of mechanisms. These include direct modeling of PA, parental support for child PA, parenting style, family cohesion, and family structure. The impact of these parental influences on child PA has been evaluated in comprehensive reviews by Gustafson and Rhodes [43] and Ferreira and colleagues [44].

\section{Parental PA}

According to Social Cognitive Theory [45], individuals learn behaviors by observing the behaviors of others. Consequently, it has been hypothesized that parents' PA behavior may directly influence their child's PA behavior. Presently, the research evidence is inconclusive regarding the link between parental modeling of PA and child activity. Gustafson and Rhodes [43] reviewed the literature examining the influence of parent activity on child activity and showed that approximately half of the studies reported a positive association between parent and child PA, with the other half reporting no association.

\section{Parental Support for PA}

Parents have the ability to influence their child's PA by providing activity-related support. Parental support comes in a variety of forms, including providing PA-related advice to the child, letting the child know they care about their PA behaviors, discussing PA and observing their child during PA, providing verbal encouragement for PA participation, and signing their child up for PA programs and providing transportation to recreational facilities (e.g., parks). Based on the findings of Gustafson and Rhodes [43], overall, there is strong evidence linking parental support with child PA, with 18 of the 19 reviewed studies demonstrating a positive association between parental support and child PA.

\section{Parenting Style}

In addition to specific parenting practices and behaviors, an overall pattern of parenting or parenting style, may influence children's PA behavior. Parenting style captures two important elements of parenting - warmth and control [46]. Categorizing parents according to whether they are high or low on parental warmth and control creates a typology of four parenting styles: authoritative, authoritarian, permissive, and neglectful [47]. An authori- 
tative parenting style is characterized by high levels of control and warmth; authoritarian is characterized by high control and low warmth; permissive is classified by low control and high warmth; and neglectful parenting is classified by low displays of both control and warmth [47].

Only three studies, to date, have examined the relation between parenting style and child PA [48-50]. Importantly, two studies assessed only authoritative and authoritarian parenting styles, and one study assessed authoritative and non-authoritative parenting; thus providing only a limited examination of parenting style, as parenting style is typically characterized into the four mentioned typologies. Overall, there were mixed results regarding the association between parenting style and child PA. For example, Schmitz et al. [48] reported a significant association between maternal parenting style and daughter PA, but reported no association between maternal parenting style and son PA. Similarly, Chen et al. [49] reported a significant association between parenting style and boys PA, but no association for girls PA.

\section{Family Cohesion}

Another family level construct that may impact children's PA behavior is family cohesion. Family cohesion is defined as the 'emotional bonding that family members have toward one another' [51]. Given the evidence linking family cohesion to other positive health behaviors in youth [52], it is reasonable to hypothesize that families who function more cohesively may create a positive environment that provides more opportunities and support for engagement in regular PA.

Our review of the literature identified few studies investigating the impact of family cohesion on child PA behavior. Factors assessing family cohesion included family expressiveness, family control, family conflict, family functioning, family bonding, family connectedness, and parent-child communication. Overall, there were mixed results regarding the association between family cohesion and child PA [53-57].

\section{Family Structure}

Family structure is also likely to be another important parental influence on children's PA behavior. Although there is great variability across studies in the operationalization of family structure [58], the most frequently studied family structure variables include parental status (i.e., single-parent or two-parent family) and number of children in the household. Based on the findings of Ferreira and colleagues [44], parental status was unrelated to child PA, with 3 of the associations being positive and significant and 17 finding no associations. Similarly, the number of children in the household was unrelated to child PA, with 0 positive and significant associations and 11 finding no associations.

Overall, the current body of evidence from observational studies suggests that parents can positively influence their child's participation in PA by providing appropriate support for PA. This can be accomplished by parents actively playing with their child, watching their child perform PA, signing their child up for PA programs, providing transportation to parks and other activity-related facilities, providing reinforcement for PA participation, and teaching their child how to play active games and sports.

\section{Parental Influences on Sedentary Behavior}

As shown, parents have the capacity to influence children's PA behavior by providing sufficient levels of parental support for PA. However, very little is known about how parents can influence children's sedentary behavior. Current evidence, although limited, suggests that parents can reduce the amount of time children engage in sedentary behavior by providing adequate support for PA. 
Leatherdale and Wong [59] examined the relation between parental support for PA and TV viewing among 25,060 high students in Ontario, Canada. They found adolescents were $12 \%$ less likely to watch more than $2 \mathrm{~h}$ of TV per day if their parents were very supportive of their PA. Contrary to these findings, Springer and colleagues [60] reported that family support for PA was not related to time spent watching TV among 718 6th grade girls. The conflicting results between these two studies may be a reflection of the assessment of support for PA, as Leatherdale and Wong [59] measured parental support, whereas Springer and colleagues [60] assessed overall family support.

Other possible parental influences for reducing children's sedentary behavior include parental limits on the time their child spends in sedentary behaviors and the monitoring of sedentary behaviors. Although these strategies have yet to be extensively evaluated, they are consistent with theoretical expectations [45]. Providing some insight into how these parental variables influence child health behaviors, Arredondo and colleagues [61] examined the relationship between parental monitoring of sedentary behavior as well as parental limit setting of sedentary behavior and child PA. Among 812 Latino children (mean age 6.0 \pm 0.94 years), parental monitoring of sedentary behavior was significantly and positively associated with child PA. Parental limit setting of sedentary behavior, however, was not related to children's PA behavior. This study demonstrated that, in addition to parental support for PA, parental monitoring of sedentary behavior can positively influence children's PA behavior. Other research supports the use of parental monitoring of sedentary behavior to increase child PA levels. For example, in a family-based intervention on electronic media use, children in the experimental group set electronic media use goals and used a TV allowance device (which controlled the amount of time the TV was allowed to be turned on) to reduce electronic media use. Compared to those in the control group, at 10 weeks, children in the experimental group increased their step counts by 543 steps per day, whereas children in the control group decreased their daily steps by 340 [62].

\section{Family-Based Interventions Targeting Change in Child PA Behavior}

A number of PA interventions targeting parents and children have been successful in increasing children's PA behavior; however, some have not. Key strategies employed by successful family-based interventions include: i) teaching parents how to monitor their child's PA levels by indicating on an activity data sheet when their child participated in PA based on set criteria [63]; ii) teaching parents to administer fitness tests and family contingency contracts, which were negotiated between the parent and child [63]; and iii) having parents encourage their child's PA and exercise with their child $[64,65]$.

O'Connor and colleagues [66] reviewed the family-based PA intervention literature, observing that the most frequent method for involving parents was sending educational materials to the family's home (31\%) and through organized activities (26\%). The least frequent methods included contacting parents via telephone (9\%), family counseling or parent training (17\%), and family exercise programs (17\%). Overall, there was limited evidence for the effectiveness of family-based interventions. Only $11 \%$ of the studies had a positive effect on children's PA. Furthermore, there was no obvious pattern to identify which family involvement methods resulted in positive PA behavior change. The authors concluded that these findings are likely a result of the heterogeneity of study design, study quality, and the outcome measures employed. As suggested by other researchers [67], other possible reasons for the lack of evidence for family-based interventions at increasing child PA include targeting the wrong mediator of PA or using the wrong strategy to target the correct mediator. Before effective interventions can be developed, we need a better understanding of the relative efficacy of the different intervention delivery strategies that have been employed. 


\section{Youth Physical Activity-Related Barriers}

Recently, Pate and colleagues [68] reviewed the literature and identified common PA-related barriers in children and adolescents as well as provided possible strategies to overcome these barriers. Barriers to utilitarian (i.e., activities of daily living) PA have focused mostly on active transport and have included parent and child concerns for safety (reported in qualitative studies only), lack of planning, lack of motivation, child scheduling and time constraints, non-supportive social norms, low peer and parental support for walking or bicycling, parent schedule and time constraints related to work, convenience for parents to drive or have child ride school bus, greater support for sedentary transport, concerns about harassment from bullies and strangers (reported in qualitative studies only), school policies related to equipment and storage, logistics of coordinating passive (car or bus) and active transport, early school start times, lack of crossing guards, homework policies that result in children carrying many books home, greater traveling distance, road infrastructure, hilly terrain and heavy traffic, traffic dangers, crime danger, and weather (reported in qualitative studies only).

Barriers to structured and free-time PA may differ between boys and girls, as girls may be more likely to report barriers such as embarrassment, sweating, fear of injury, and weight criticism by peers and family member compared to boys. Other demographic barriers include age (older children report homework and lack of time as barrier), socioeconomic status (SES) (children from lower SES report higher barriers of cost, distance to facilities, safety, and condition of available facilities), race/ethnicity (minority parents less likely report their neighborhood as being safe), and weight status (overweight children report more barriers). Other barriers of structured or free-play activities include not having others to participate in PA with, having friends who are not active, family obligations, low priority compared with social needs, negative experiences while being active with peers, intimidated by the social environment, lack of parental or peer support, parental restrictions, coaching problems, aggressive players, teachers discouraging sports participation, emphasis on competition, unavailability of school facilities, job responsibilities, activities that are not of interest to children, increased interest of sedentary behaviors, expense of activities, concerns about safety, and poor weather.

As recommended by Pate and colleagues [68], possible strategies to overcome these barriers include the implementation of programs to promote PA, implementation of policies to ensure safe travel routes and neighborhoods, making facilities more accessible for children in terms of scheduling, transportation and affordability, parental control of their child's access to sedentary behaviors, parental support for outdoor play, parental modeling of PA and ensuring homes have available equipment for PA.

\section{Conclusion}

Current empirically based evidence demonstrates that regular participation in PA during childhood has numerous immediate benefits, including positive changes in adiposity, skeletal health, psychological health, and cardiorespiratory fitness. Additionally, motor skill development during early childhood may have immediate health benefits as well as longlasting effects in adulthood. Furthermore, the benefits of PA during childhood also appear to positively influence adult health outcomes, such as increased bone mineral density. However, despite these benefits, a significant proportion of children are not meeting the current 60-min MVPA guideline, and, as a result, we are in dire need of effective programs and policies to promote PA among children. Key environmental settings that have been 
shown to influence children's PA behavior and therefore could be targeted for activity behavior change include child care, active commuting to and from school, school recess, school physical education, after-school programs, churches, medical settings, and the home environment.

\section{Recommendations for Practitioners}

For school-based settings, it has been shown that physical education programs can be modified so as to increase the percentage of class time devoted to MVPA. Key strategies include providing in-service training opportunities to improve instructional practices and teaching cooperative games and activities that include all students. Offering a wider variety of developmentally appropriate PAs that cater to the needs and interests of students is also an important strategy. During the early elementary years, educators should develop young children's movement skills, and during the middle-school and high-school years, physical educators should teach key behavioral skills such as goal setting, enlisting support for PA, and self-monitoring. Schools can also promote PA during recess through the use of brightly colored playground markings and having teachers initiate active games with fitness breaks integrated into the games. Additionally, given the link between enjoyment of PA and PA participation rates, it is important for practitioners to not force children to engage in PA, as this may reduce their enjoyment of PA. For the home setting, parents should be encouraged to establish and monitor PA goals, provide appropriate rewards for meeting these goals, monitor their child's sedentary behavior, and provide sufficient support for their child's PA. For community-based environments such as religious institutions or healthcare settings, staff can integrate activity-friendly lessons into the curriculum, and physicians and other healthcare professionals can use stage-appropriate written materials coupled with counseling to promote PA among children. Additional strategies have been published elsewhere [69].

\section{Recommendations for Researchers}

To improve our understanding of the relation between PA and health in children, additional large-scale longitudinal studies are needed. When feasible, studies should use objective measures of PA, such as accelerometers or pedometers. Given the lack of effective community-based PA interventions in children, additional community-based interventions need to be developed and evaluated. For new studies, particular attention should be focused on recruiting an adequate sample size for sufficient power, having an adequate follow-up of participants, using reliable and valid outcome measures, and providing an assessment of intervention fidelity [70]. Additionally, future studies are encouraged to examine the effectiveness of PA-based interventions in minority racial-ethnic groups and children of low SES, as these populations are in the greatest need of intervention. Although there is no shortage of family-based PA interventions, we still do not know what is the best method to involve parents in family-based interventions. Family-based interventions examining the effects of different parental involvement methods are needed to answer this important question.

\section{Disclosure Statement}

The authors declare no conflict of interest. 
Loprinzi et al.: Benefits and Environmental Determinants of Physical Activity in

Children and Adolescents

\section{References}

1 CDC: Physical activity levels among children aged 9-13 years - United States, 2002. MMWR 2003;52:785788.

2 Twisk JW: Physical activity guidelines for children and adolescents: a critical review. Sports Med 2001;31: 617-627.

3 Pan Y, Pratt CA: Metabolic syndrome and its association with diet and physical activity in US adolescents. J Am Diet Assoc 2008;108:276-286; discussion 286.

- 4 Veltsista A, Kanaka C, Gika A, Lekea V, Roma E, Bakoula C: Tracking of overweight and obesity in Greek youth. Obes Facts 2010;3:166-172.

5 Telama R: Tracking of physical activity from childhood to adulthood: a review. Obes Facts 2009;2:187-195.

6 Blair SN, Clark DG, Cureton KJ, Powell KE. Exercise and fitness in childhood: implications for a lifetime of health; in Gisolfi CV, Lamb DR (eds): Perspectives in Exercise Science and Sports Medicine. New York, McGraw-Hill, 1989, pp 401-430.

7 Brill PA, Burkhalter HE, Kohl HW, Blair SN, Goodyear NN: The impact of previous athleticism on exercise habits, physical fitness, and coronary heart disease risk factors in middle-aged men. Res Q Exerc Sport 1989;60:209-215.

$\checkmark 8$ Fehily AM, Coles RJ, Evans WD, Elwood PC. Factors affecting bone density in young adults. Am J Clin Nutr 1992;56:579-586.

9 Telama R, Yang X, Laakso L, Viikari J: Physical activity in childhood and adolescence as predictor of physical activity in young adulthood. Am J Prev Med 1997;13:317-323.

-10 Stodden DF, Goodway JD, Langendorfer SJ, Roberton MA, Rudisill ME, Garcia C, Garcia LE: A developmental perspective on the role of motor skill competence in physical activity: An emergent relationship. Quest 2008;60:290-306.

11 Clark JE, Metcalfe JS: The mountain of motor development: a metaphor; in Clarke JE, Humphrey JH (eds) Motor Development: Research and Reviews. Reston, National Association of Sport and Physial Education, 2002, pp 163-190.

12 Harter S: Effectance motivation reconsidered: toward a developmental model. Hum Dev 1978;21:34-64.

13 Matvienko 0, Ahrabi-Fard I: The effects of a 4-week after-school program on motor skills and fitness of kindergarten and first-grade students. Am J Health Promot 2010;24:299-303.

$\checkmark 14$ Barnett L, Van Beurden E, Morgan P, Brooks L, Beard J: Does childhood motor skill proficiency predict adolescent fitness. Med Sci Sports Exerc 2008;40:2137-2144.

-15 Stodden DF, Langendorfer SJ, Roberton MA, Kelbley L: Association between motor skill competence and health-related physical fitness. J Sport Exerc Psychol 2007;29:S45.

16 US Department of Health and Human Services: 2008 Physical Activity Guidelines for Americans. October 2008. www.health.gov/paguidelines/.

17 Eaton DK, Kann L, Kinchen S, Shanklin S, Ross J, Hawkins J, et al: Youth risk behavior surveillance - United States, 2007. MMWR Surveill Summ 2008;57:1-131.

18 Kjonniksen L, Torsheim T, Wold B: Tracking of leisure-time physical activity during adolescence and young adulthood: A 10-year longitudinal study. Int J Behav Nutr Phys Act 2008;5:69.

19 Marshall SJ, Gorely T, Biddle SJ: A descriptive epidemiology of screen-based media use in youth: a review and critique. J Adolesc 2006;29:333-349.

20 Faulkner GE, Buliung RN, Flora PK, Fusco C: Active school transport, physical activity levels and body weight of children and youth: a systematic review. Prev Med 2009;48:3-8.

21 Bailey RC, Olson J, Pepper SL, Porszasz J, Barstow TJ, Cooper DM: The level and tempo of children's physical activities: an observational study. Med Sci Sports Exerc 1995;27:1033-1041.

22 Ridgers ND, Stratton G, Fairclough SJ: Physical activity levels of children during school playtime. Sports Med 2006;36:359-371.

-23 Stratton G: Promoting children's physical activity in primary school: an intervention study using playground markings. Ergonomics 2000;43:1538-1546.

24 Stratton G, Leonard J: The metabolism of the elementary school playground: the effects of an intervention study on children's energy expenditure. Ped Exerc Sci 2002;14:170-180.

25 Stratton G, Mullan E: The effect of multicolor playground markings on children's physical activity level during recess. Prev Med 2005;41:828-833.

26 Scruggs PW, Beveridge SK, Watson DL: Increasing children's school time physical activity using structured fitness breaks. Ped Exerc Sci 2003;15:156-169.

27 Connolly P, McKenzie TL: Effects of a games intervention on the physical activity levels of children at recess. Res Q Exerc Sport 1995;66(suppl):A-60.

28 Gordon-Larsen P, McMurray RG, Popkin BM: Determinants of adolescent physical activity and inactivity patterns. Pediatrics 2000;105:1-8.

29 Lee SM, Burgeson CR, Fulton JE, Spain CG: Physical education and physical activity: Results from the school health policies and programs study 2006. J Sch Health 2007;77:435-463.

-30 Dowda M, James F, Sallis JF, McKenzie TL, Rosengard P, Kohl HW 3rd: Evaluating the sustainability of SPARK physical education: a case study of translating research into practice. Res Q Exerc Sport 2005;76:11-19. 
Loprinzi et al.: Benefits and Environmental Determinants of Physical Activity in

Children and Adolescents

-31 Luepker RV, Perry CL, McKinlay SM, Nader PR, Parcel GS, Stone EJ, et al: Outcomes of a field trial to improve children's dietary patterns and physical activity. The Child and Adolescent Trial for Cardiovascular Health. CATCH Collaborative Group. JAMA 1996;275:768-776.

-32 Pate RR, Ward DS, Saunders RP, Felton G, Dishman RK, Dowda M: Promotion of physical activity among high-school girls: a randomized controlled trial. Am J Public Health 2005;95:1582-1587.

33 Beets MW, Beighle A, Erwin HE, Huberty JL: After-school program impact on physical activity and fitness: a meta-analysis. Am J Prev Med 2009;36:527-537.

-34 Pate RR, Trost SG, Mullis R, Sallis JF, Wechsler H, Brown DR: Community interventions to promote proper nutrition and physical activity in youth. Prev Med 2000;31(suppl):S138-149.

-35 Jago R, Baranowski T: Non-curricular approaches for increasing physical activity in youth: a review. Prev Med 2004;39:157-163.

36 Baranowski T, Baranowski JC, Cullen KW, Thompson DI, Nicklas T, Zakeri IE, et al: The Fun, Food, and Fitness Project (FFFP): the Baylor GEMS pilot study. Ethn Dis 2003;13(suppl):S30-39.

-37 Pate RR, Saunders RP, Ward DS, Felton G, Trost SG, Dowda M: Evaluation of a community-based intervention to promote physical activity in youth: lessons from Active Winners. Am J Health Promot 2003;17: 171-182.

-38 King AC: Community intervention for promotion of physical activity and fitness. Exerc Sport Sci Rev 1991; 19:211-259.

39 Resnicow K, Jackson A, Blissett D, Wang T, McCarty F, Rahotep S, et al: Results of the healthy body healthy spirit trial. Health Psychol 2005;24:339-348.

40 Eakin EG, Glasgow RE, Riley KM: Review of primary care-based physical activity intervention studies: effectiveness and implications for practice and future research. J Fam Pract 2000;49:158-168.

-41 Patrick K, Calfas KJ, Norman GJ, Zabinski MF, Sallis JF, Rupp J, et al: Randomized controlled trial of a primary care and home-based intervention for physical activity and nutrition behaviors: PACE+ for adolescents. Arch Pediatr Adolesc Med 2006;160:128-136.

-42 Ortega-Sanchez R, Jimenez-Mena C, Cordoba-Garcia R, Munoz-Lopez J, Garcia-Machado ML, VilasecaCanals J: The effect of office-based physician's advice on adolescent exercise behavior. Prev Med 2004;38: 219-226.

43 Gustafson SL, Rhodes RE: Parental correlates of physical activity in children and early adolescents. Sports Med 2006;36:79-97.

44 Ferreira I, van der Horst K, Wendel-Vos W, Kremers S, van Lenthe FJ, Brug J: Environmental correlates of physical activity in youth - a review and update. Obes Rev 2007;8:129-154.

45 Bandura A: Social Foundations of Thought and Action: A Social Cognitive Theory. Englewood Cliffs, Prentice Hall, 1986.

46 Baumrind D: Effects of authoritative parental control on child behavior. Child Dev 1966;37:887-907.

47 Maccoby EE, Martin, B: Socialization in the context of the family: parent-child interaction; in Hetherington EM (ed): Handbook of Child Psychology. New York, Wiley, 1983, pp 1-101.

-48 Schmitz KH, Lytle LA, Phillips GA, Murray DM, Birnbaum AS, Kubik MY: Psychosocial correlates of physical activity and sedentary leisure habits in young adolescents: the Teens Eating for Energy and Nutrition at School study. Prev Med 2002;34:266-278.

49 Chen J, Kennedy C: Family functioning, parenting style, and Chinese children's weight status. J Fam Nurs 2004;10:262-279.

50 Gable S, Lutz S: Household, parent, and child contributions to childhood obesity. Fam. Rel. 2000;49:293300.

-51 Olson DH, Russell CS, Sprenkle DH: Circumplex model of marital and family systems: VI. theoretical update. Family Process 1983;22:69-84.

52 Franko DL, Thompson D, Bauserman R, Affenito SG, Striegel-Moore RH: What's love got to do with it? Family cohesion and healthy eating behaviors in adolescent girls. Int J Eat Disord 2008;41:360-367.

53 Moore J, Harre N: Eating and activity: the importance of family and environment. Health Promot J Austr 2007;18:143-148.

54 Mackey ER, Streisand R: Brief report: the relationship of parental support and conflict to physical activity in preadolescents with type 1 diabetes. J Pediatr Psychol 2008;33:1137-1141.

55 Adkins S, Sherwood NE, Story M, Davis M: Physical activity among African-American girls: the role of parents and the home environment. Obes Res 2004;12(suppl):38S-45S.

$\checkmark 56$ Sallis JF, Nader PR, Broyles SL, Berry CC, Elder JP, McKenzie TL, et al. Correlates of physical activity at home in Mexican-American and Anglo-American preschool children. Health Psychol 1993;12:390-398.

57 Ornelas IJ, Perreira KM, Ayala GX: Parental influences on adolescent physical activity: a longitudinal study. Int J Behav Nutr Phys Act 2007;4:3.

58 Lee GR: Family Structure and Interaction: A Comparative Analysis. '2nd revised' ed. Minneapolis, University of Minnesota Press, 1982.

-59 Leatherdale ST, Wong SL: Modifiable characteristics associated with sedentary behaviours among youth. Int J Pediatr Obes 2008;3:93-101.

60 Springer AE, Kelder SH, Hoelscher DM: Social support, physical activity and sedentary behavior among 6th-grade girls: a cross-sectional study. Int J Behav Nutr Phys Act 2006;3:8. 
61 Arredondo EM, Elder JP, Ayala GX, Campbell N, Baquero B, Duerksen S: Is parenting style related to children's healthy eating and physical activity in Latino families? Health Educ Res 2006;21:862-871.

-62 Todd MK, Reis-Bergan MJ, Sidman CL, Flohr JA, Jameson-Walker K, Spicer-Bartolau T, Wildeman K: Effect of a family-based intervention on electronic media use and body composition among boys aged 8-11 years: a pilot study. J Child Health Care 2008;12:344-358.

-63 Taggart AC, Taggart J, Siedentop D: Effects of a home-based activity program. A study with low fitness elementary school children. Behav Modif 1986;10:487-507.

64 Ransdell LB, Taylor A, Oakland D, Schmidt J, Moyer-Mileur L, Shultz B: Daughters and mothers exercising together: effects of home- and community-based programs. Med Sci Sports Exerc 2003;35:286-296.

65 Conwell LS, Trost SG, Spence L, Brown WJ, Batch JA: The feasibility of a home-based moderate-intensity physical activity intervention in obese children and adolescents. Br J Sports Med 2010;44:250-255.

66 O'Connor TM, Jago R, Baranowski T: Engaging parents to increase youth physical activity a systematic review. Am J Prev Med 2009;37:141-149.

67 Baranowski T, Anderson C, Carmack C: Mediating variable framework in physical activity interventions. How are we doing? How might we do better? Am J Prev Med 1998;15:266-297.

68 Pate R, Saunders RP, O’Neill JR, Dowda M: Overcoming barriers to physical activity: helping youth be more active. ACSM's Health \& Fitness Journal 2011;15:7-12.

69 CDC: Guidelines for school and community programs to promote lifelong physical activity among young people. MMWR 1997;46(No. RR-3):1-36.

70 Campbell K, Waters E, O'Meara S, Summerbell C: Interventions for preventing obesity in childhood. A systematic review. Obes Rev 2001;2:149-157. 